\title{
Cancer in an ileoanal reservoir: a new late complication?
}

\author{
H Stern, S Walfisch, B Mullen, R McLeod, Z Cohen
}

\begin{abstract}
The functional success rate of the ileoanal reservoir procedure for ulcerative colitis is quite high. Despite the few early and late complications described there is now widespread acceptance of this procedure in the management of ulcerative colitis. We report a patient who developed an adenocarcinoma in the rectal cuff four years after having a pelvic pouch procedure. This new late complication brings to light several points including the importance of a radical total mucosectomy. The purpose of this paper is to discuss concern as to whether or not this procedure is indicated in colitis patients in whom severe dysplasia is the primary indication for surgery.
\end{abstract}

Abdominal colectomy, rectal mucosectomy and ileoanal pouch anastomosis has gained increased acceptance as an alternative to total proctocolectomy and end ileostomy in the management of ulcerative colitis. A concern about this procedure is the fate of any islets of rectal mucosa left behind or regenerated in the cuff of rectal muscle stripped of its mucosa. The literature suggests that residual islets of mucosa appear in up to $20 \%$ of these procedures. ${ }^{1}$ Regeneration of islets, however, does not seem to occur. ${ }^{2}$ This concern is particularly relevant in patients in whom the indication for surgery is severe dysplasia. $^{3}$

The increased risk of developing colonic carcinoma in patients with ulcerative colitis has been known for many years, especially in younger age groups who have had more extensive colitis for longer than 20 years. ${ }^{45}$ Cancer in colitis is frequently a fatal illness whch is entirely preventable by a total colectomy. ${ }^{3} \mathrm{~A}$ recent report suggests that a pelvic pouch is indicated even in the presence of colonic cancer providing that the cancer does not invade the pelvic floor muscles and the resection margins do not damage the sphincter mechanism. ${ }^{6}$

\section{Case report}

We report the first patient to have undergone a total colectomy, rectal mucosectomy and ileoanal pelvic pouch anastomosis, who subsequently developed a cancer in the residual rectal cuff. This 59 year old man was diagnosed as having ulcerative colitis at age 21 . He was well for 28 years until 1977 when he was found to have

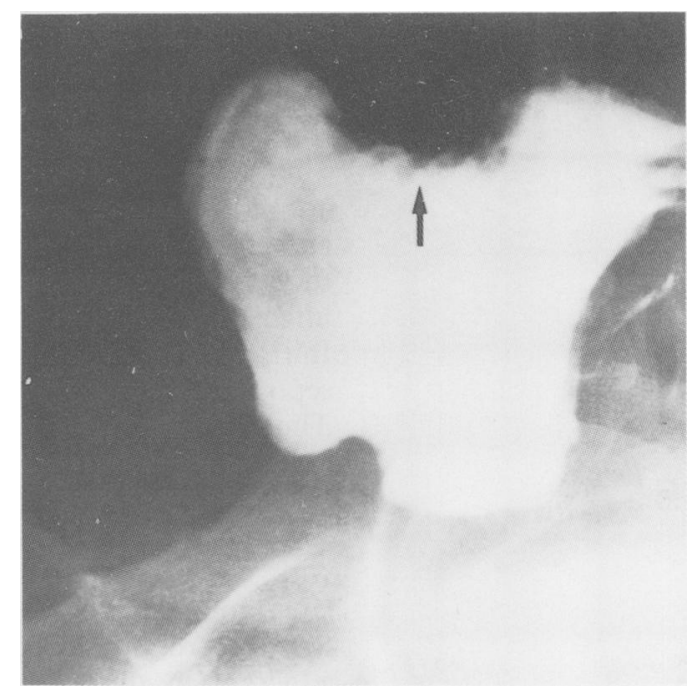

Figure 1: Pouchogram showing left lateral defect caused by cancer invasion.

severe dysplasia. He underwent a subtotal colectomy with ileorectal anastomosis. The pathology revealed an occult cancer of the ascending colon (Dukes C). In 1984 (seven years later), he developed severe dysplasia in the remaining rectum. The remaining proximal rectum was excised and a distal mucosal proctectomy with a J-type ileoanal reservoir procedure was performed.

He remained well for three years until 1987 when he developed symptoms of frequent loose bowel motions, weight loss of $20 \mathrm{~kg}$, and fatigue. Investigations included pouch endoscopies with biopsies, pouchography, computed tomography scan and stool cultures. The findings included minimal pouchitis, and a slight indentation change in the pouch on pouchography (Fig 1)

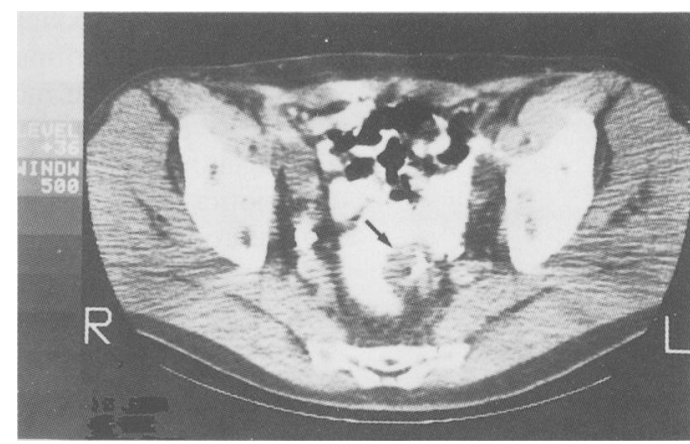

Figure 2: Computed tomography of pelvis showing same defect on left lateral wall of pouch. 


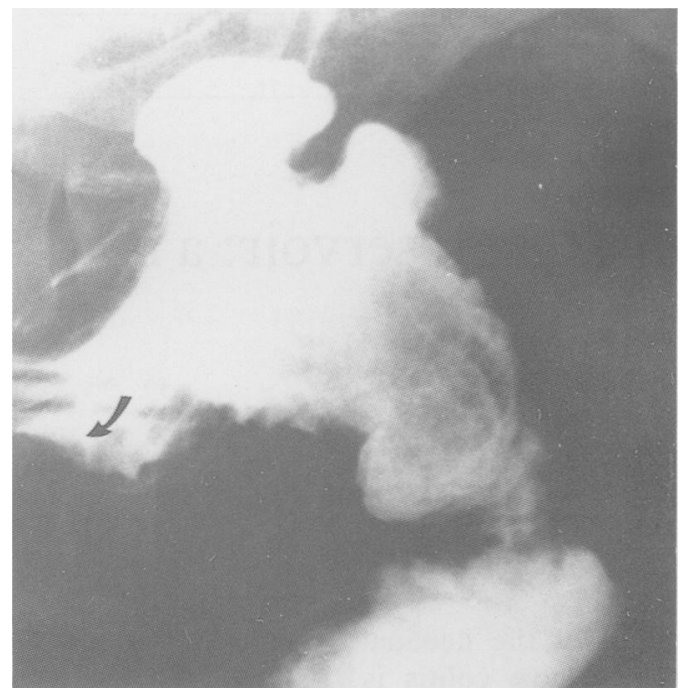

Figure 3: Left lateral view of pouchogram pointing on long efferent limb.

and computed tomography scan (Fig 2). Symptoms were attributed to a presumed pouch infection, although no pathogens were isolated. Initial management included: metronidazole, septra, vancomycin, and pouch intubation. There was little clinical improvement.

The problem was thought to be structural and related to late stricturing of the efferent end of the pouch (Fig 3). A laparotomy was performed with the intention of correcting this. At laparotomy a solid sheet of adenocarcinoma was found surrounding and invading the pouch and adherent to the sacrum (Fig 4). A palliative procedure was performed in which the pouch was excised and an end ileostomy was performed.

\section{Discussion}

The technical problem of leaving behind some mucosal tissue at the time of rectal mucosectomy has concerned several authors including ourselves. ${ }^{2579} \mathrm{We}$ consider the rectal mucosectomy to be an especially critical part of the procedure, precisely because of the theoretical cancer risk. Nevertheless, despite the care we took with this particular aspect of the procedure a cancer has occurred. It is therefore important to try and put this new 'late' complication in perspective.

The overall success rate success rate of the ileoanal reservoir operation is quite high. Mortality rate is low $(0 \%)$ in our hands. There is still a significant early morbidity with this procedure such as anastomotic leaks and strictures in $10 \%$ of the cases. ${ }^{89-12}$ The most important late complication is pouchitis. A current clinical definition is inflammatory dysfunction of the pouch due to one or more causes. It occurs in up to $20 \% " 11$ of cases, may or may not show a pathogen but is usually successfully treated with antibiotics. A further $15 \%$ of patients ${ }^{12}$ simply do not function well for reasons not well understood.

Nevertheless overall success rates in cumulative series are over $88 \% .^{9-14}$ Furthermore in those series in which the issue was assessed, most patients, even those with complications, preferred life with the reservoir to one with an ileostomy. ${ }^{9}{ }^{12} 13$ This overall experience must therefore be considered when assessing the sig-

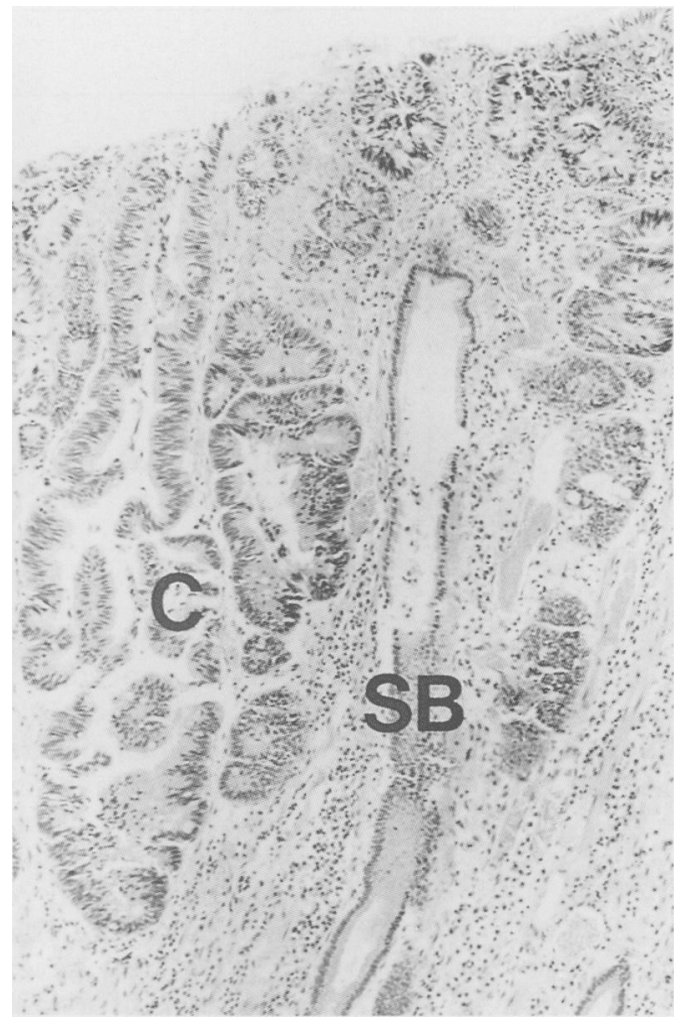

Figure 4: Section from ileal pouch demonstrating normal smal bowel glands $(S B)$ mixed with carcinoma $(C)$.

nificance of our experience with this one patient.

Although it is dangerous to draw conclusions from a single case report, we believe that it is reasonable to consider the following three points. First, since this procedure was first introduced there has been a lag period, during which cancers may now be developing. If there is an increase in reporting of such cases, we might reconsider the wisdom of the ileoanal procedure for colitis patients who have severe dysplasia. Second, in patients who have had the procedure and develop late non-specific symptoms of pouch dysfunction, the diagnosis of cuff cancer should be entertained. Third, the importance of a meticulous mucosectomy cannot be over emphasised.

1 Heppell J, Weiland LH, Perrault J, Pemberton JH, Telander $\mathrm{RL}$, Beart RW Jr. Fate of the rectal mucosa after recta mucosectomy and ileoanal anastomosis. Dis Colon Rectum 1983; 26: 768-71.

2 O'Connell PR, Pemberton JH, Weiland LH, et al. Does rectal mucosa regenerate after ileoanal anastomosis? Dis Colo Rectum 1987; 30: 1-5.

3 Collins RH Jr, Feldman M, Fordtman JS. Colon cancer, dysplasia, and surveillance in patients with ulcerative colitis: a critical review. N Engl F Med 1987; 316: 1654-8.

4 Maratka Z, Nedbal J, Kocianova I, Havelka I, Kudrmann J, Hendl J. Incidence of colorectal cancer in procto colitis: a retrospective study of 959 cases over 40 years. Gut 1985; 26 : 43-9.

5 Nugent FW, Haggitt RC, Colcher H, Kutterut GG. Malignant potential of chronic ulcerative colitis. Preliminary report Gastroenterology 1979; 76: 1-5.

6 Taylor BA, Wolff BG, Dozois GR, Kelly KA, Pemberton JH Beart RW. Ileal pouch anal anastomosis for chronic ulcerative colitis and familial polyposis colitis complicated by adenocarcinoma. Dis Colon Rectum 1988; 31: 358-62

7 Bubrick MP, Jacobs DM, Levy M. Experience with the endorectal pull-through and $S$ pouch for ulcerative colitis and familial polyposis in adults. Surgery 1985; 98: 689-99.

8 Fleshman JW, Cohen Z, McLeod RS, Stern H, Blair J. Th ileal reservoir and ileoanal anastomosis procedure. Factors affecting technical and functional outcome. Dis Colon Rectum 1988; 31: 10-6.

9 Utsunomiya I, Iwama T, Imajo M, et al. Total colectomy, mucosal proctectomy and ileoanal anastomosis. Dis Colon Rectum 1980; 23: 459-66. 
10 Metcalf AM, Dozois RR, Kelly KA, Beart RW, Wolff BG. Ileal ' $i$ ' pouch-anal anastomosis-clinical outcome. Ann Surg 1985; 202: 735-9.

11 Cohen Z, McLeod RS, Stern H, Grant D, Nordgran S. The pelvic pouch and ileoanal anastomosis procedure. Surgical technique and initial results. Am 7 S urg 1985; 150: 601-7.

12 Grant D, Cohen Z, McHugh S, McLeod R, Stern H.
Restorative proctocolectomy-clinical results and manometric findings with long and short rectal cuffs. Dis Colon Rectum 1986; 29: 27-32.

13 Nicholls RJ. Restorative proctocolectomy with various types of reservoir. World F Surg 1987; 11: 751-62.

14 Taylor BA, Dozois RR. The $\mathrm{j}$ ileal pouch and anastomosis 